\title{
A lower apatinib dose provides equivalent efficacy and reduced toxicity: A phase II, single-arm study of apatinib and oral etoposide in metastatic breast cancer
}

\section{Nanlin Hu}

Chinese Academy of Medical Sciences and Peking Union Medical College

\section{Anjie Zhu}

Chinese Academy of Medical Sciences and Peking Union Medical College

\section{Yiran Si}

Chinese Academy of Medical Sciences and Peking Union Medical College Jian Yue

Chinese Academy of Medical Sciences and Peking Union Medical College

\section{Xue Wang}

Chinese Academy of Medical Sciences and Peking Union Medical College

\section{Jiayu Wang}

Chinese Academy of Medical Sciences and Peking Union Medical College

\section{Fei Ma}

Chinese Academy of Medical Sciences and Peking Union Medical College

\section{Binghe Xu}

Chinese Academy of Medical Sciences and Peking Union Medical College

Peng Yuan ( $\square$ yuanpeng01@hotmail.com )

Chinese Academy of Medical Sciences and Peking Union Medical College

\section{Research}

Keywords: apatinib, oral etoposide, HER2-negative breast cancer,angiogenesis

Posted Date: April 30th, 2020

DOl: https://doi.org/10.21203/rs.3.rs-25022/v1

License: (c) (1) This work is licensed under a Creative Commons Attribution 4.0 International License. Read Full License 


\section{Abstract}

\section{Background:}

The effectiveness of antiangiogenic drugs in metastatic breast cancer(MBC) is still unclear. Apatinib is a small tyrosine kinase inhibitor that inhibits vascular endothelial growth factor receptor 2 (VEGFR-2). We performed this clinical trial to evaluate the efficacy and safety of apatinib and oral etoposide in patients with HER2-negative locally advanced or MBC.

\section{Methods:}

Patients with HER2-negative MBC previously treated with anthracycline and taxanes and failed $\geq 1$ prior chemotherapy regimens were recruited. The starting dose of apatinib was $500 \mathrm{mg}$ and $425 \mathrm{mg}$ in patients with Eastern Cooperative Oncology Group (ECOG) scores of $0-1$ and 2, respectively. The etoposide capsules were given at $50 \mathrm{mg} / \mathrm{m}^{2}$ on days 1 to 10 for 21 days. The primary end point was progressionfree survival (PFS) which is assessed every 6 weeks (RECIST v1.1). Secondary end points included objective response rate (ORR), disease control rate (DCR), overall survival (OS), and safety.

\section{Results:}

Thirty-one eligible patients were enrolled. The median follow-up time was 11 months. The median PFS for all patients was 6.93 months (95\% confidence interval (Cl), 5.97-7.90), and 6.93 months $(95 \% \mathrm{Cl} 5.27-$ $8.60)$ and 6.56 months $(95 \% \mathrm{Cl} 1.41-11.73)$ for patients with apatinib $425 \mathrm{mg}$ and $500 \mathrm{mg}$ once daily, respectively. The ORR was 35.5\% (11/31). The DCR was $87.1 \%$ (27/31). The median OS was 20.37 months $(95 \% \mathrm{Cl}, 11.39-29.34)$. The median PFS of patients who had hypertension and proteinuria was longer than that for those without hypertension and proteinuria. The most common grade $3 / 4$ treatmentrelated adverse events(AE) were hypertension (12/31, 38.71\%), fatigue (3/31, 9.68\%), thrombocytopenia $(3 / 31,9.68 \%)$.

\section{Conclusion:}

Apatinib combined with etoposide capsules is effective and tolerable in heavily pretreated, metastatic HER2-negative breast cancer patients. A lower apatinib dose provide equivalent efficacy and reduced toxicity.

\section{Introduction}

Breast cancer is the most common malignant tumour and the second leading cause of cancer-related death in women worldwide [1]. The median survival time of patients after metastasis is 9 months to 3 years [2, 3]. In China, HER2-negative breast cancer accounts for approximately $65 \%$ of all breast cancers [4]. which has no specific targeted drug for this type of breast cancer.The treatment for HER2-negative metastatic breast cancer, especially in second and later lines, requires more new drugs or combined regimens. 
Tumour angiogenesis is closely related to tumour growth and metastasis, , and antiangiogenic strategies are some of the most important strategies for advanced breast cancer. Bevacizumab has shown some efficacy in the treatment of metastatic breast cancer, and chemotherapy as a first-line and second-line treatment for HER2-negative advanced breast cancer has significantly extended median progression-free survival (PFS) $[5,6]$. Preclinical studies have shown that antiangiogenic drugs combined with chemotherapy can improve the efficacy of chemotherapeutic drugs and reverse the resistance of tumour cells [7-9], which indicates this combination therapy may be a potential treatment.

Apatinib is an oral small molecule tyrosine kinase inhibitor(TKI) that selectively inhibits vascular endothelial growth factor receptor 2(VEGFR2), which exhibits some efficacy in in triple-negative and nontriple-negative metastastic breast cancer by monotherapy $[10,11]$. Oral etoposide is one of the options for patients with metastatic breast cancer, achieving a median PFS of 5 months and a median overall survival(OS) of 16 months with manageable toxicity [12]. We suppose that apatinib and etoposide capsules are effective and tolerablein patients with breast cancer.

Therefore, this study aimed to explore the efficacy and safety of apatinib combined with etoposide capsules in pretreated metastatic HER2-negative breast cancerpatients from the NCT03535961 trial.

\section{Methods}

\subsection{Study designand participants}

Patients included in the trial were 18-to-75-year-old females with histologically or cytologically diagnosed HER2-negative locally advanced or metastatic breast cancerwho received at least one regimen of chemotherapy after metastasis, includinga taxane and anthracycline, with an Eastern Cooperative Oncology Group (ECOG) performance status of 0-2. The patients had measurable lesions as defined by the Response Evaluation Criteria In Solid Tumors (RECIST) 1.1.Patients who had previously received small molecule anti-angiogenic TKIs and patients with uncontrolled hypertension were excluded from the trial.

The study was approved by the Ethics Committee of the Cancer Hospital of the Chinese Academy of Medical Sciencesandperformed in accordance with the Declaration of Helsinki. Every patient signed written informed consent.

\subsection{Procedures}

The starting dose of apatinib was $500 \mathrm{mg}$ and $425 \mathrm{mg}$ in patients with ECOG scores of $0-1$ and 2, respectively,and apatinib was taken orally each day. The etoposide capsules were given at $50 \mathrm{mg} / \mathrm{m}^{2}$ on days 1 to 10 for 21 daysper cycle.The tumour response was evaluated every 6 weeks according to RECIST v1.1 until the disease progressed or intolerable adverse reactions occurred. Blood pressure was monitored twice a day for the first 3 weeks and at least once a day after blood pressure stabilized. 
Routine blood and urine tests were performed weekly, physical examinations were performed every 3 weeks, liver and kidney functions were monitored, and electrocardiograms and tumour marker tests were performed every 6 weeks.

Dosage adjustment was recommended if haematological toxicity above grade 3 or nonhematological toxicity above grade 2 (except for hair loss) occurred, including withdrawal and reduction.

The first reduced dose was $425 \mathrm{mg} /$ day and the second reduced dose was $250 \mathrm{mg} /$ day for patients with an apatinib starting dose of $500 \mathrm{mg}$. Patients with a starting dose of $425 \mathrm{mg}$ were adjusted to $250 \mathrm{mg} /$ day first and $250 \mathrm{mg}$ every other day second. The first and second adjustments of etoposide dose were $35 \mathrm{mg} / \mathrm{m}^{2}$ on $\mathrm{d} 1-10$ and $35 \mathrm{mg} / \mathrm{m}^{2}$ on d1 -7 , respectively. When adverse reactions of grade 3 and above occurred, dose adjustments were made according to the protocol. When adverse reactions were of grade 2 or below, researchers were allowed to adjust the doses according to the specific conditions. Adverse events were graded using Common Terminology Criteria for Adverse Events (CTCAE) 4.0.

\subsection{Outcome}

The primary endpoint of this study was progression-free survival(PFS), and the secondary endpoints were overall survival(OS), safety, objective response rate(ORR) and disease control rate(DCR). The PFS duration was defined as the interval between the initiation of treatment and disease progression. The overall survival duration was defined as the interval between the initiation of treatment and death for any reason.

\subsection{Statistical Analysis}

Simon's two-stage design with a one-sided $\alpha=0.05$ and $80 \%$ test efficiency was used to determine the number of patients that needed to be enrolled [13]. Previous studies have shown that the ORR of apatinib monotherapy for patients with metastatic non-triple-negative breast cancer is $16.7 \%$, and the ORR of etoposide capsule monotherapy is $21.3 \%[10,14]$. We estimated thatthe response rate of apatinib combined with etoposide was $40 \%$. Under such conditions, at least 2 of 10 patients needed to respond for the trial to move to the next stage. Another 21 patients needed to be recruited in the second stage, for a total of 31 patients. If 10 or more patients responded to this therapy, the regimen would be considered a success.

Patients receiving $\geq 1$ cycle of apatinib were included for survival and safety analysis. PFS and OS were estimated based on a Kaplan-Meier curve. A log-rank test was used to compare the mPFS in different subgroups. Factors with $p<0.1$ in the Kaplan-Meier single factor analysis were included in the Cox regression model for analysis. SPSS 23.0 and GraphPad Prism 7.0 were used for data analysis. 


\section{Results}

Thirty-four patients were screened from May 2017 to May 2019. Two patients withdrew their informed consent. Because 1 patient had only bone metastases and no measurable lesions, 31 patients were included in the final survival and safety analyses (Fig. 1). The basic clinicopathologicaland median PFS data are shown in Table 1. 
Table 1

Patients characteristics and mPFS in subgroups.

\begin{tabular}{|c|c|c|c|}
\hline Overall & All Patients enrolled(\%) & mPFS (months, 95\%Cl) & $P$ Value \\
\hline Number & 31 & $6.93(5.97-7.90)$ & \\
\hline Age & $47(34-65)$ & & \\
\hline$\geq 50$ & $14(45.16)$ & 7.03(2.84-11.22) & 0.65 \\
\hline$<50$ & $17(54.84)$ & $6.43(4.42-8.45)$ & \\
\hline \multicolumn{4}{|c|}{ Hormone receptor status } \\
\hline Positive & 19(61.29) & $7.40(6.03-8.76)$ & \multirow[t]{2}{*}{0.04} \\
\hline Negative & 12(38.71) & $3.13(1.04-5.22)$ & \\
\hline \multicolumn{4}{|c|}{ Axillary lymph node metastasis } \\
\hline Positive & $22(70.97)$ & $4.43(0.00-13.90)$ & \multirow[t]{2}{*}{0.21} \\
\hline Negative & $9(29.03)$ & $6.93(6.09-7.78)$ & \\
\hline \multicolumn{4}{|l|}{ TNM stage } \\
\hline I & $3(9.68)$ & 14.73 & \multirow[t]{3}{*}{0.16} \\
\hline II & $17(54.84)$ & $7.03(6.02-8.04)$ & \\
\hline III & $11(35.48)$ & $4.00(0.00-8.93)$ & \\
\hline \multicolumn{4}{|c|}{ ECOG performance status } \\
\hline $0-1$ & $16(51.61)$ & $6.93(5.27-8.60)$ & \multirow[t]{2}{*}{0.56} \\
\hline 2 & $15(48.39)$ & $6.56(1.41-11.73)$ & \\
\hline \multicolumn{4}{|c|}{ Metastasis site } \\
\hline no visceral & $10(32.26)$ & $7.03(4.74-9.33)$ & \multirow[t]{2}{*}{0.82} \\
\hline Visceral & $21(67.74)$ & $6.57(3.43-9.71)$ & \\
\hline \multicolumn{4}{|c|}{ Lines of Chemotherapy } \\
\hline 2 & $11(35.48)$ & $6.57(3.42-9.71)$ & \multirow[t]{3}{*}{0.82} \\
\hline 3 & $11(35.48)$ & $6.93(0.43-13.44)$ & \\
\hline$\geq 4$ & $9(29.04)$ & 7.03(3.59-10.48) & \\
\hline \multicolumn{4}{|c|}{ Apatinib dose } \\
\hline $425 \mathrm{mg}$ & 15(48.39) & $6.93(5.27-8.60)$ & \multirow[t]{2}{*}{0.56} \\
\hline $500 \mathrm{mg}$ & 16(51.61) & $6.56(1.41-11.73)$ & \\
\hline
\end{tabular}




\begin{tabular}{|c|c|c|c|}
\hline Overall & All Patients enrolled(\%) & mPFS (months, 95\% Cl) & $P$ Value \\
\hline \multicolumn{4}{|c|}{ Apatinib dose reduction } \\
\hline No & 12(38.71) & $5.83(2.71-8.96)$ & \multirow[t]{2}{*}{0.59} \\
\hline Yes & 19(61.29) & 7.40(1.84-12.96) & \\
\hline \multicolumn{4}{|c|}{ Hypertension } \\
\hline No & $7(22.58)$ & $2.60(2.17-3.02)$ & \multirow[t]{2}{*}{0.02} \\
\hline Yes & $24(77.42)$ & $7.40(5.96-8.44)$ & \\
\hline \multicolumn{4}{|c|}{ Hand-foot skin reaction } \\
\hline No & $17(54.84)$ & $6.93(5.14-8.73)$ & \multirow[t]{2}{*}{0.46} \\
\hline Yes & $14(45.16)$ & $6.57(2.13-11.00)$ & \\
\hline \multicolumn{4}{|c|}{ Proteinuria } \\
\hline No & $16(51.61)$ & $4.00(0.13-7.87)$ & \multirow[t]{2}{*}{0.04} \\
\hline Yes & $15(48.39)$ & $8.10(2.35-13.85)$ & \\
\hline \multicolumn{4}{|c|}{ Mucositis } \\
\hline No & $25(80.65)$ & $6.57(4.95-8.18)$ & \multirow[t]{2}{*}{0.79} \\
\hline Yes & $6(19.35)$ & 11.53 & \\
\hline
\end{tabular}

\subsection{Efficacy}

The median follow-up time was 10.30 months (95\% confidence interval (Cl) 3.50-24.33). All patients had breast invasive ductal carcinoma, with a median age of 47 years (34-65); Treatment was discontinued in 25 patients due to disease progression, and 6 patients continued to receive treatmentuntil the cut-off day. According to the RECIST 1.1 guidelines, no patients achieved a complete response in this study, 11 patients (35.5\%) achieved a partial response(PR), the ORR was 35.5\% (11/31), 16 (51.6\%) patients achieved stable disease(SD) (Table 2), and 22 patients (71.0\%) patients had tumour shrinkage of different degrees (Fig. 2). The DCR was 87.1\% (27/31), the median PFS was 6.93 months $(95 \% \mathrm{CI} 5.97-$ 7.90) (Fig. 3), and the clinical efficacy of initial apatinib doses of $500 \mathrm{mg}$ and $425 \mathrm{mg}$ in patients is shown in Table 2. 
Table 2

Clinical response to apatinib and oral estoposide therapy

\begin{tabular}{|llll|}
\hline Treatment Efficacy & total & apatinib $500 ~ m g(n=16)$ & apatinib 425 $\mathbf{m g}(\mathbf{n}=15)$ \\
\cline { 2 - 4 } & $\mathbf{n}(\%)$ & $\mathbf{n}(\%)$ & $\mathbf{n}(\%)$ \\
\hline Partial Response & $11(35.5)$ & $7(43.75)$ & $4(26.67)$ \\
\hline Stable Disease & $16(51.6)$ & $8(50.00)$ & $8(53.33)$ \\
\hline Disease progression & $4(12.9)$ & $1(6.25)$ & $3(20.00)$ \\
\hline Overall Response & $11(35.5)$ & $7(43.75)$ & $4(26.67)$ \\
\hline Disease Control & $27(87.1)$ & $15(93.75)$ & $12(80.00)$ \\
\hline median PFS $(\mathrm{m})$ & $6.93(5.97-7.90)$ & $6.56(1.41-11.73)$ & $6.93(5.27-8.60)$ \\
\hline
\end{tabular}

16(51.6\%) patients with an ECOG score of 2 received an apatinib dose of $425 \mathrm{mg}$, and 15(48.4\%) patients with an ECOG score of 0-1 received an apatinib dose of $500 \mathrm{mg}$; the median PFS was 6.93 months (95\% $\mathrm{Cl} 5.27-8.60)$ and 6.56 months ( $95 \% \mathrm{Cl} 1.41-11.73$ ),respectively, with a p value of 0.56 , which has no statistical significance. The mPFS of hormone receptor-positive and hormone receptor-negative patients was 7.40 months $(6.03-8.76)$ and 3.13 months $(1.04-5.22, p=0.04)$, respectively. There was no significant difference in MPFS between patients with and without visceral metastases $(p=0.82)$. There were 11 (35.48\%), 11 (35.48\%), and 9 (35.48\%) patients who had received 1, 2, and 3 chemotherapy regimens, respectively. Their mPFS values were 6.57 months (95\% Cl 3.42-9.71), 6.93 (95\% Cl 0.43$13.44)$ and $7.03(95 \% \mathrm{Cl} 3.59-10.48, \mathrm{P}=0.82)$, respectively. The results of the subgroup analysis are shown in Table 2. Factors with $p<0.1$ in the univariate analysis were included in the multivariate analysis, and the HR of hormone receptor status on mPFS was $2.354(95 \% \mathrm{Cl} 0.903-6.135 ; \mathrm{p}=0.08)$, which reach a marginal statistical significance.The results of thesubgroup analysis are shown in Table 1.

As of the date of data analysis, 17 patients were still alive, with a median OS of 20.37 months $(95 \% \mathrm{Cl}$ 11.39-29.34).

\subsection{Safety}

Most of the adverse reactions were mild to moderate(Table 3 ) and were well controlled after treatment. The most common grade $3-4$ adverse events were hypertension (38.71\%), fatigue (9.68\%), and thrombocytopenia (9.68\%). No adverse events related death or serious adverse events was reported. Grade 3-4 hypertensionin patients was reduced to below $140 / 90 \mathrm{mmHg}$ after receipt of antihypertensive drugs. 
Table 3

Treatment-related adverse events in the safety population.

\begin{tabular}{|c|c|c|c|c|c|c|}
\hline \multirow[t]{2}{*}{ Adverse Event } & \multicolumn{3}{|c|}{ apatinib $500 \mathrm{mg}(n=16)$} & \multicolumn{3}{|c|}{ apatinib $425 \mathrm{mg}(n=15)$} \\
\hline & Total & $\begin{array}{l}\text { Grade 1- } \\
2(\%)\end{array}$ & $\begin{array}{l}\text { Grade 3- } \\
4(\%)\end{array}$ & Total & $\begin{array}{l}\text { Grade 1- } \\
2(\%)\end{array}$ & $\begin{array}{l}\text { Grade 3- } \\
\text { 4(\%) }\end{array}$ \\
\hline \multicolumn{7}{|l|}{$\begin{array}{l}\text { Non- } \\
\text { Haematological }\end{array}$} \\
\hline hypertension & $12(75.00)$ & $4(25.00)$ & $8(25.8)$ & $12(80.00)$ & $8(53.33)$ & $4(26.67)$ \\
\hline proteinuria & $10(62.50)$ & $10(62.50)$ & 0 & $5(33.33)$ & $4(26.67)$ & $1(6.67)$ \\
\hline $\begin{array}{l}\text { Hand-foot } \\
\text { syndrome }\end{array}$ & $13(81.25)$ & $13(81.25)$ & 0 & $5(33.33)$ & $5(33.33)$ & 0 \\
\hline Mucositis & $5(31.25)$ & $5(31.25)$ & 0 & $1(6.67)$ & $1(3.23)$ & 0 \\
\hline Fatigue & $8(50.00)$ & $6(37.50)$ & $2(12.50)$ & $3(20.00)$ & $2(6.45)$ & $1(3.23)$ \\
\hline Diarrhoea & $0(0)$ & 0 & 0 & $1(6.67)$ & $1(6.67)$ & 0 \\
\hline Vomiting & $11(68.75)$ & $10(62.50)$ & $1(6.25)$ & $7(46.67)$ & $7(46.67)$ & 0 \\
\hline Nausea & $12(75.00)$ & 11(68.75) & $1(6.25)$ & $10(66.67)$ & $10(66.67)$ & 0 \\
\hline Alopecia & $7(43.75)$ & $7(43.75)$ & 0 & $5(33.33)$ & $5(33.33)$ & 0 \\
\hline Hyperbilirubinaemia & $3(18.75)$ & $3(18.75)$ & 0 & $2(13.33)$ & $2(13.33)$ & 0 \\
\hline Aminotransferase & $6(37.50)$ & $6(37.50)$ & 0 & $2(13.33)$ & $1(6.67)$ & $1(6.67)$ \\
\hline \multicolumn{7}{|l|}{ increased } \\
\hline \multicolumn{7}{|l|}{ Haematological } \\
\hline Neutropenia & $14(8.75)$ & $13(81.25)$ & $1(6.25)$ & $10(66.67)$ & $9(60.00)$ & $1(6.67)$ \\
\hline Anaemia & $2(12.50)$ & $2(12.50)$ & 0 & $3(20.00)$ & $3(20.00)$ & 0 \\
\hline Thrombocytopenia & $4(25.00)$ & $3(18.75)$ & $1(6.25)$ & $5(33.33)$ & $3(9.68)$ & $1(6.67)$ \\
\hline
\end{tabular}

Twelve(38.7\%) patients experienced apatinib dose reductions due to adverse events. Of these, 5 patients were in the apatinib $500 \mathrm{mg}$ group (1 with neutropenia, 1 with hypertension, 1 with hand-foot syndrome, and 2 with fatigue), of which 4 patients received 2 dose reductions, and 7 patients were in the $425 \mathrm{mg}$ group (1 with thrombocytopenia, 1 with hypertension, 1 with asthenia, 2 with proteinuria, and 2 with handfoot reaction) and received one apatinib dose reduction. Eleven (35.5\%) patients had their doses modified during or at the end of the first cycle, and five (16.13\%) (four patients had a second dose reduction) had their doses modified at the end of the second cycle. Two patients underwent dose adjustment for etoposide capsules. 
A stratified analysis of each adverse event suggested that the occurrence of hypertension and proteinuria may be a positive predictor of response.We found that the median PFS in patients with hypertension was significantly longer than that in patients without hypertension[7.40 months ( $95 \% \mathrm{Cl} 5.96-8.44)$ versus 2.60 months (95\% Cl 2.17-3.02), Hazard Ratio(HR) 0.28 (95\% Cl 0.09-0.83), $p=0.022$ )]; mPFS was also significantly longer in patients with proteinuria than those without proteinuria $(8.10$ months $(95 \% \mathrm{Cl}$ 2.35-13.85) versus 4.00 months ( $95 \% \mathrm{Cl} 0.13-7.87)$, $\mathrm{HR} 0.38$ (95\% $\mathrm{Cl} 0.15-0.94), p=0.036$ )(Fig. 4A-B).

\section{Discussion}

This study first explored the application of apatinib combined with etoposide capsules in locally advanced and metastatic HER2-negative breast cancer. In this study, the ORR was 35.5\%, the median PFS was 6.93 months, and the median OS was 20.37 months.

The median PFS associated withapatinib monotherapy for metastatic non-triple-negative breast cancer and triple-negative breast cancer was 4.0 months ( $95 \% \mathrm{Cl} 2.8-5.2)$ and 3.3 months( $95 \% \mathrm{Cl} 1.7-5.0)$, respectively $[10,11]$. In previous studies, the median PFS associated with etoposide monotherapy for advanced breast cancer was between 2.6 and 5.0 months, and the median OS was between 11.0 and 24.0 months $[12,14-16]$. Although this study has limitations in comparison with other studies directly, it can be seen from the data that the median PFS and median OS were longer in patients who received apatinib and etoposide capsules than in those who received either one of the two drugs alone.

Antiangiogenic drugs combined with chemotherapy increased the PFS in locally advanced and metastatic HER2-negative breast cancer after second-line treatment. The results of this study are equivalent to or even better thanthose of similar studies. In the RIBBON-2 study, the median PFS was 7.2 months with standard chemotherapy regimens combined with bevacizumab for the second-line treatment of patients with metastatic HER2-negative breast cancer [6]. Treatment with gemcitabine or capecitabine combined with sorafenib yielded an median PFS of 3.4 months as a first-line treatment after metastasis in breast cancer patients [17]. Most of the antiangiogenic drugs and chemotherapy drugs tested so far have obtained a small benefit in terms of the median PFS, but no clinical benefit of OS has been seen yet. However, the occurrence of adverse events is greatly increased, which has substantially limited the use of such regimens in clinical practice. In this study, we achieved a median PFS of 6.93 months and a median OS of 20.37 months. The response was comparable to or even better than that insimilar studies, and the adverse reactions were manageable that no bleeding or febrile neutropenia occurred. At the same time, Chinese scholars have shown that apatinib combined with etoposide capsules has achieved good results in advanced ovarian cancer,in which the median PFS was 8.1 months, the ORR reached 54\% (19/35), and the toxicities were well tolerated [18]. In addition, apatinib and etoposide capsules are administered orally, which reduces the durationand the cost of hospitalization, so this combination is suggested to be one of the treatment options for patients with locally advanced and metastatic breast cancer.

In this study, different starting doses of apatinib were given on the basis of the patient's ECOG score. There was no significant difference in the median PFS (6.56 months vs 6.93 months, $p=0.56)$ in the 
$500 \mathrm{mg}$ group and $425 \mathrm{mg}$ group, but fewer adverse events were observed in the $425 \mathrm{mg}$ group. Therefore, we recommend $425 \mathrm{mg}$ apatinib as the starting dose for combination therapy. In addition, there was no significant difference in the median PFS between patients treated in the second-line, thirdline, or further in this study protocol $(p=0.82)$, indicating that apatinib and etoposide capsules can be used in patients who progress after multiline treatment.

In previous studies, the single dose of apatinib was 500-850 mg once per day. We observed in our clinical practice that some patients were intolerant to the $500 \mathrm{mg}$ dose in the combination strategy of chemotherapy and apatinib. Therefore, we administered $500 \mathrm{mg}$ once daily to patients with superior physical status and $425 \mathrm{mg}$ once daily to patients with relatively worse status. For etoposide capsules, previous clinical research has recommended $50 \mathrm{mg}-60 \mathrm{mg} / \mathrm{m}^{2}$ for 14 consecutive days or 10 days in a 21-day cycle. We learned from clinical experience that most patients were unable to tolerate the dosage. Considering that our research protocol used a combination treatment, we choose the $50 \mathrm{mg} / \mathrm{m} 2 / \mathrm{d}$ on $\mathrm{d} 1$ 10 and a 21-day cycle as the starting dose for etoposide. Nonetheless, $38.7 \%$ of apatinib was taken in reduced doses due to intolerable adverse reactions.

It is worth noting that this study showed that the occurrence of hypertension and proteinuria may be a positive predictor for efficacy. Previous studies have shown that the occurrence of adverse reactions such as hypertension and proteinuria may be one of the predictive markers for the efficacy of antiangiogenic drugs. In a clinical study of sunitinib in advanced renal cell carcinoma [19], patients with hypertension had longer PFS and OS than patients without hypertension (median OS 41.6 versus 16.4 months, $p<$ 0.0001 , medianPFS 12.9 versus 5.6 months, $p<0.0001$, respectively). A cohort study of patients with metastatic gastric cancer treated with apatinib showed that the mPFS was prolonged by 24.5 days ( 86.5 versus 62 days) in patients who developed adverse reactions such as hypertension, proteinuria, and hand-foot syndrome within 4 weeks of taking the drug, and the median OS was extended by 2.2 months [20]. In our study, further analysis showed that the mPFS was prolonged by 4.8 months in patients with hypertension receiving apatinib and etoposide $(p=0.022)$, and the mPFS in patients with proteinuria was extended by 4.1 months $(p=0.036)$, but there was no statistically significant difference in overall survival. The trends of adverse reactions and curative effects in this study are consistent with previous studies, and it is worth expanding the sample size for further research.

This study did have some limitations. First, the number of patients enrolledwas small, and there was a lack of control cases. Second, there might be bias in the population because this is a single-arm, singlecentre clinical trial.

\section{Conclusion:}

In summary, this study demonstrates that apatinib combined with etoposide capsules has a good effect in the second-line treatment of HER2-negative locally advanced and metastatic breast cancer with tolerable adverse reactions, suggesting that the combination deserves further phase III clinical research. 


\section{List Of Abbreviations}

MBC metastatic breast cancer

HER2 human epidermal growth factor receptor 2

VEGFR2 vascular endothelial growth factor receptor 2

TKI tyrosine kinase inhibitor

ECOG Eastern Cooperative Oncology Group

RECIST Response Evaluation Criteria In Solid Tumors

PFS progression free survival

OS overall survival

ORR objective response rate

DCR disease control rate

Cl confidencial interval

AE adverse event

HR hazard ratio

PR partial response

SD stable disease

CTCAE Common Terminology Criteria for Adverse Events

\section{Declarations}

\section{Ethics approval and consent to participate}

The study was approved by the Ethics Committee of the Cancer Hospital of the Chinese Academy of Medical Sciencesandperformed in accordance with the Declaration of Helsinki. Every patient signed written informed consent.

\section{Consent for publication}

Every patient signed written informed consent. 
Not applicable

\section{Competing interests}

The authors declare that they have no competing interests

\section{Funding}

This work was supported by National Natural Science Foundation of China [grant numbers 81472753 , 81672634], and National Key Research and Development Program of China[grant number 2018YFC0115204].

\section{Authors' contributions}

PY proposed ideas and designed studies study concepts, and review manuscript. Conception and design were performed by BHX, PY, JYW, and FM. All authors have contribution in collection and assembly of data. Data analysis and interpretation were done by NLH, AJZ, YRS, JY, XW. NLH was a major contributor in writing the manuscript All authors read and approved the final manuscript.

\section{Acknowledgements}

Not applicable

\section{References}

1. Siegel RL, Miller KD, Jemal A. Cancer statistics, 2019. CA Cancer J Clin. 2019;69(1):7-34.

2. Fan L, Strasser-Weippl K, Li JJ, St Louis J, Finkelstein DM, Yu KD, et al. Breast cancer in China. Lancet Oncol. 2014;15(7):e279-89.

3. Stuckey A. Breast cancer: epidemiology and risk factors. Clin Obstet Gynecol. 2011;54(1):96-102.

4. Wang Q, Li J, Zheng S, Li JY, Pang Y, Huang R, et al. Breast cancer stage at diagnosis and area-based socioeconomic status: a multicenter 10-year retrospective clinical epidemiological study in China. BMC Cancer. 2012;12:122.

5. Robert NJ, Dieras V, Glaspy J, Brufsky AM, Bondarenko I, Lipatov ON, et al. RIBBON-1: randomized, double-blind, placebo-controlled, phase III trial of chemotherapy with or without bevacizumab for first-line treatment of human epidermal growth factor receptor 2-negative, locally recurrent or metastatic breast cancer. J Clin Oncol. 2011;29(10):1252-60.

6. Brufsky AM, Hurvitz S, Perez E, Swamy R, Valero V, O'Neill V, et al. RIBBON-2: a randomized, doubleblind, placebo-controlled, phase III trial evaluating the efficacy and safety of bevacizumab in combination with chemotherapy for second-line treatment of human epidermal growth factor receptor 2-negative metastatic breast cancer. J Clin Oncol. 2011;29(32):4286-93.

7. Mi YJ, Liang YJ, Huang HB, Zhao HY, Wu CP, Wang F, et al. Apatinib (YN968D1) reverses multidrug resistance by inhibiting the efflux function of multiple ATP-binding cassette transporters. Cancer Res. 
2010;70(20):7981-91.

8. Tong XZ, Wang F, Liang S, Zhang X, He JH, Chen XG, et al. Apatinib (YN968D1) enhances the efficacy of conventional chemotherapeutical drugs in side population cells and ABCB1-overexpressing leukemia cells. Biochem Pharmacol. 2012;83(5):586-97.

9. Zhang Q, Song Y, Cheng X, Xu Z, Matthew OA, Wang J, et al. Apatinib Reverses Paclitaxel-resistant Lung Cancer Cells (A549) Through Blocking the Function of ABCB1 Transporter. Anticancer Res. 2019;39(10):5461-71.

10. Hu X, Cao J, Hu W, Wu C, Pan Y, Cai L, et al. Multicenter phase Il study of apatinib in non-triplenegative metastatic breast cancer. BMC Cancer. 2014;14:820.

11. Hu X, Zhang J, Xu B, Jiang Z, Ragaz J, Tong Z, et al. Multicenter phase II study of apatinib, a novel VEGFR inhibitor in heavily pretreated patients with metastatic triple-negative breast cancer. Int $\mathrm{J}$ Cancer. 2014;135(8):1961-9.

12. Yuan $P, X u B H$, Wang JY, Ma F, Fan Y, Li Q, et al. Oral etoposide monotherapy is effective for metastatic breast cancer with heavy prior therapy. Chin Med J (Engl). 2012;125(5):775-9.

13. Simon R. Optimal two-stage designs for phase II clinical trials. Control Clin Trials. 1989;10(1):1-10.

14. Yuan P, Di L, Zhang X, Yan M, Wan D, Li L, et al. Efficacy of oral Etoposide in pretreated metastatic breast cancer: a multicenter phase 2 study. Med (Baltim). 2015;94(17):e774.

15. Valabrega G, Berrino G, Milani A, Aglietta M, Montemurro F. A retrospective analysis of the activity and safety of oral Etoposide in heavily pretreated metastatic breast cancer patients. Breast $\mathrm{J} 2015$, 21(3):241-245.

16. Jagodic M, Cufer T, Zakotnik B, Cervek J. Selection of candidates for oral etoposide salvage chemotherapy in heavily pretreated breast cancer patients. Anticancer Drugs. 2001;12(3):199-204.

17. Crown JP, Dieras V, Staroslawska E, Yardley DA, Bachelot T, Davidson N, et al. Phase III trial of sunitinib in combination with capecitabine versus capecitabine monotherapy for the treatment of patients with pretreated metastatic breast cancer. J Clin Oncol. 2013;31(23):2870-8.

18. Lan CY, Wang Y, Xiong Y, Li JD, Shen JX, Li YF, et al. Apatinib combined with oral etoposide in patients with platinum-resistant or platinum-refractory ovarian cancer (AEROC): a phase 2, singlearm, prospective study. Lancet Oncol. 2018;19(9):1239-46.

19. Izzedine H, Derosa L, Le Teuff G, Albiges L, Escudier B. Hypertension and angiotensin system inhibitors: impact on outcome in sunitinib-treated patients for metastatic renal cell carcinoma. Ann Oncol. 2015;26(6):1128-33.

20. Liu X, Qin S, Wang Z, Xu J, Xiong J, Bai Y, et al. Early presence of anti-angiogenesis-related adverse events as a potential biomarker of antitumor efficacy in metastatic gastric cancer patients treated with apatinib: a cohort study. J Hematol Oncol. 2017;10(1):153.

\section{Figures}




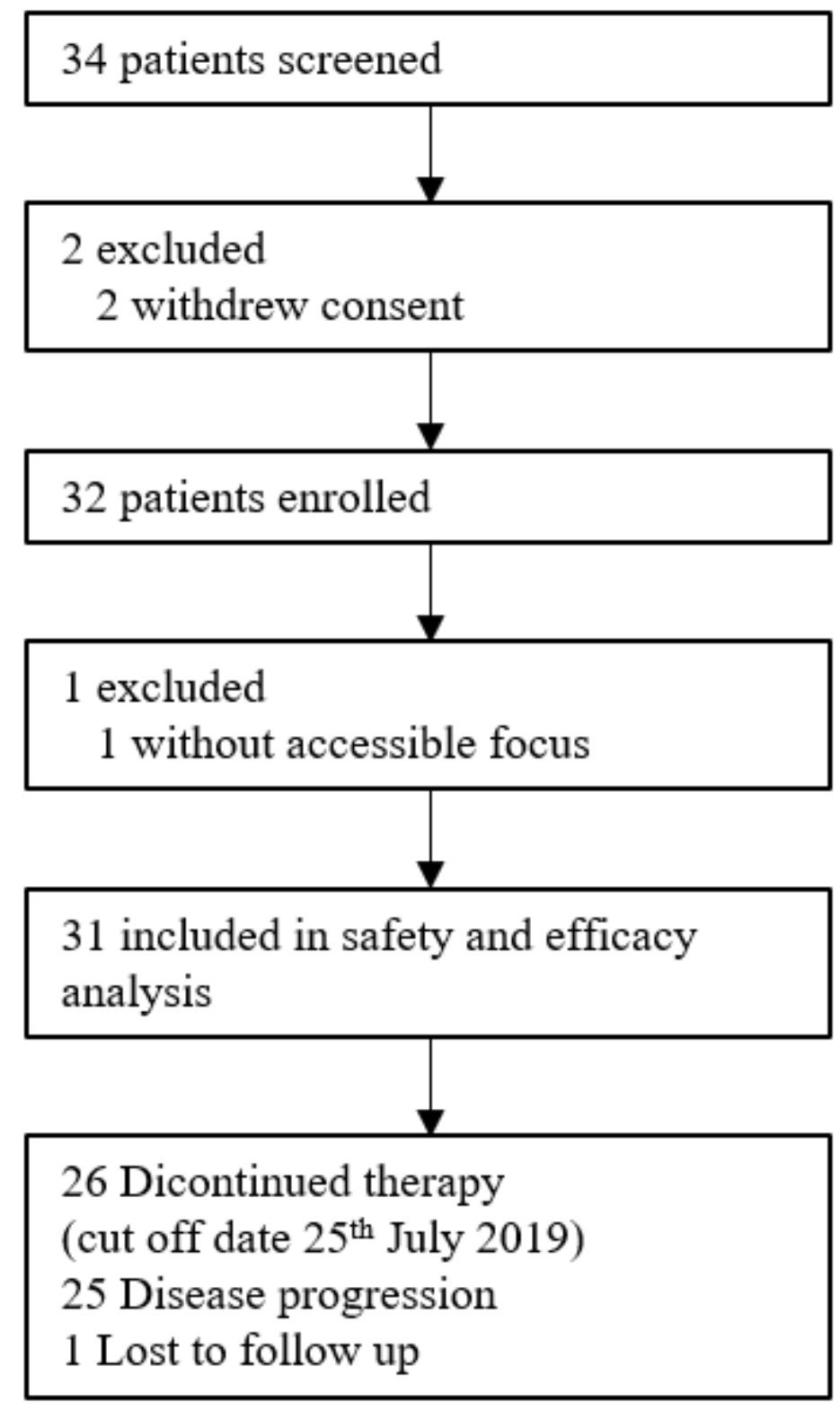

Figure 1

Clinical profile. 


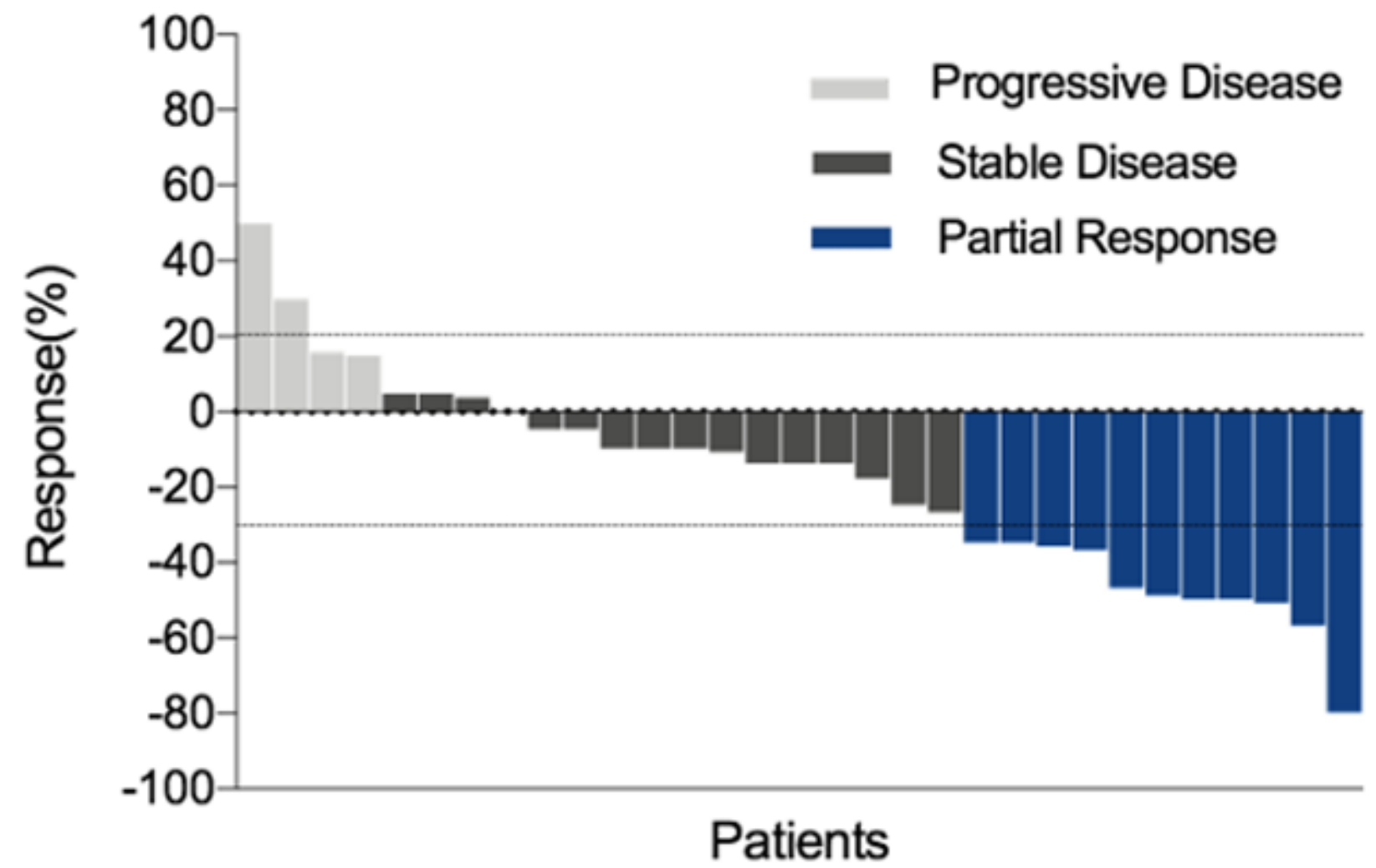

Figure 2

Waterfall plot for the best percentage change in target lesion size 
A

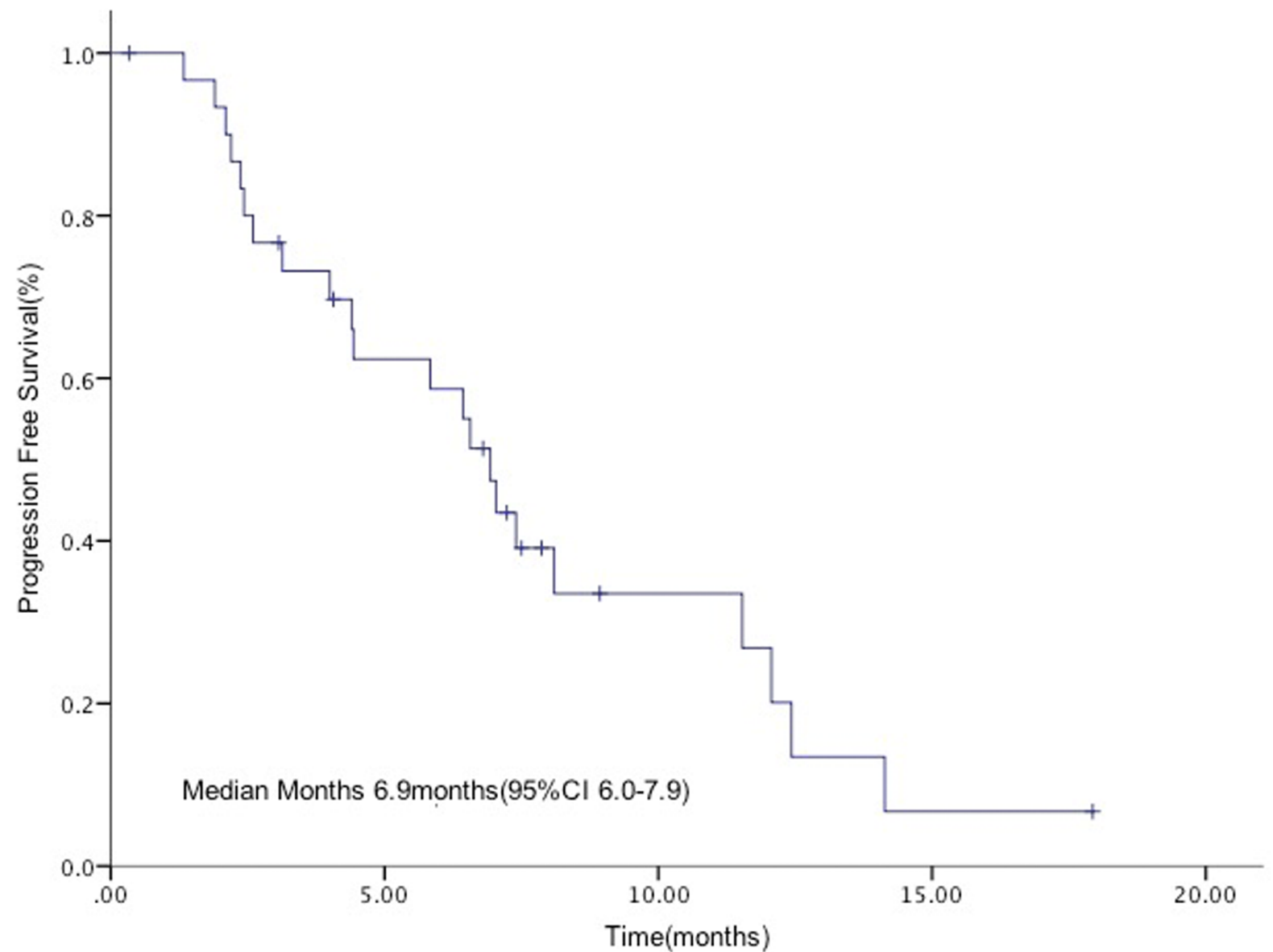

No.risk

31

17

6

1

Number censored

(0)

(3)

(4)

(4)

\section{Figure 3}

Kaplan-Meier graph for progression-free survival in all patients

A

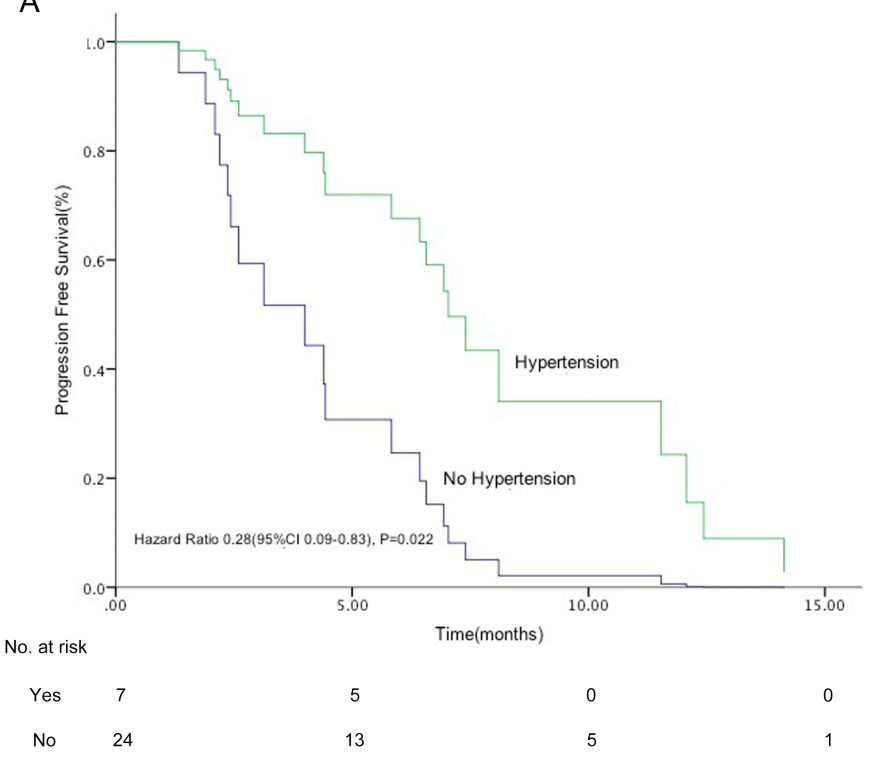

B

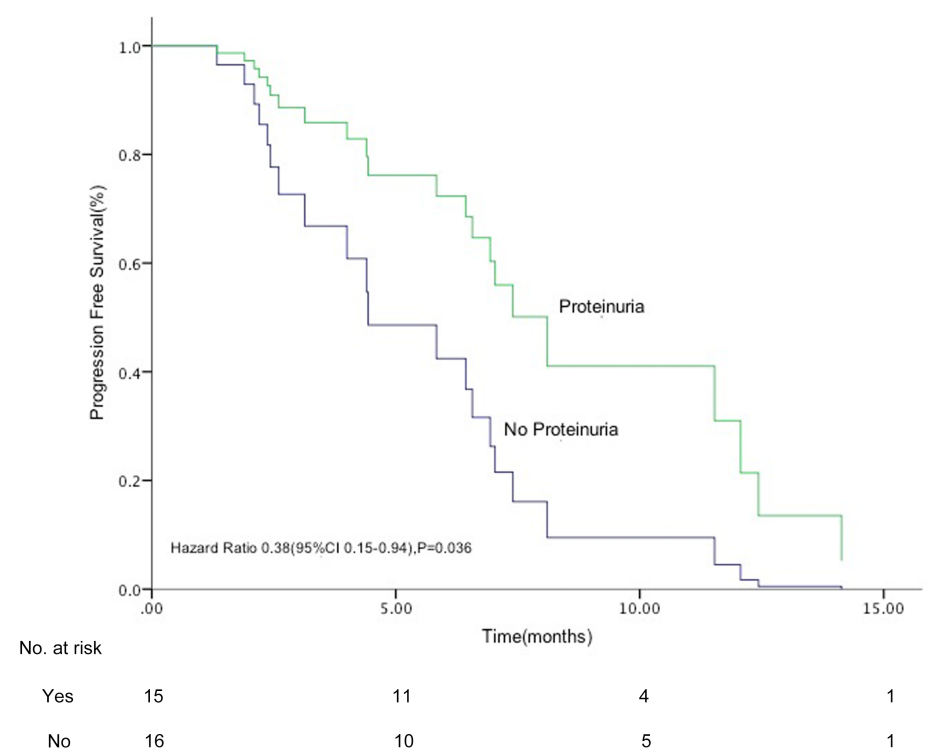




\section{Figure 4}

Kaplan-Meier graph for progression-free survival in patients who had hypertension(A) and proteinuria(B) $(n=31)$. Median PFS in patients with hypertension was significantly longer than that in patients without hypertension[7.40 months (95\% Cl 5.96-8.44) versus 2.60 months ( $95 \% \mathrm{Cl}$ 2.17-3.02), Hazard Ratio(HR) 0.28 (95\% Cl 0.09-0.83), $\mathrm{p}=0.022)](\mathrm{A})$; mPFS was also significantly longer in patients with proteinuria than those without proteinuria ( 8.10 months $(95 \% \mathrm{Cl} 2.35-13.85)$ versus 4.00 months ( $95 \% \mathrm{Cl} 0.13-7.87)$, HR 0.38 (95\% Cl 0.15-0.94), $p=0.036)(B)$. 